\title{
LOS ESCENARIOS SOCIALES DE LAS ROCAS INTERVENIDAS. APORTES DESDE LA VERTIENTE ORIENTAL DE LAS CUMBRES CALCHAQUÍES, TUCUMÁN, ARGENTINA
}

\author{
SOCIAL SETTINGS OF INTERVENED ROCKS. INSIGHTS FROM THE EASTERN \\ SLOPES OF CUMBRES CALCHAQUÍES, TUCUMÁN, ARGENTINA
}

\author{
Julián Salazar ${ }^{1}$ y Valeria Franco Salvi ${ }^{2}$
}

\begin{abstract}
Este artículo se propone analizar las características materiales y los contextos de hallazgo de un conjunto de rocas intervenidas que se manufacturaron y circularon en asentamientos del primer milenio de la Era cristiana en la localidad de Anfama, en el extremo sur de las Cumbres Calchaquíes. Los estudios arqueológicos realizados han permitido identificar los escenarios en los que participaron estas piezas, proponer relaciones cronológicas y discutir su asignación clásica como rocas asociadas exclusivamente al culto a los ancestros. Los resultados obtenidos permiten sostener que la producción y circulación de estos objetos se asocian, sobre todo, a la primera mitad del primer milenio de la Era, en un contexto de emergencia y consolidación de la vida aldeana, y que constituyeron entidades ordenadoras de las rutinas y relaciones domésticas.

Palabras claves: rocas intervenidas, contexto arqueológico, escenarios sociales, Noroeste argentino.

This paper analyses the material attributes and discovery contexts of a set of rocks that were intervened and circulated during the first Millennium of the Christian Era in settlements of the locality of Anfama, southern end of Cumbres Calchaquies. Archaeological studies have made it possible to identify the original settings where these pieces were used, to propose chronological relations, and to discuss their traditional categorization as rocks exclusively associated with the cult of ancestors. The results allow to state that the manufacture and circulation of these objects took place mostly during the first half of the first Millennium, within a context of emergence and consolidation of village life, and that they acted as ordering entities in household routines and relationships.
\end{abstract}

Key words: Intervened rocks, archaeological context, social settings, Northwest of Argentina.

Este trabajo explora las relaciones en las que determinadas rocas intervenidas asociadas tradicionalmente al culto a los ancestros, estuvieron involucradas en contextos aldeanos del primer milenio de la Era cristiana en la vertiente oriental de las Cumbres Calchaquíes (en el noroeste de la provincia de Tucumán, república Argentina). En este caso, registramos un conjunto de piezas en sus contextos depositacionales caracterizando los escenarios en los cuales recorrieron sus trayectorias de vida y los vínculos que fueron estableciendo con otras materialidades.

En diferentes contextos del mundo andino pueden reconocerse variedades de piedras esculpidas, grabadas y/o pulidas que fueron interpretadas como objetos centrales en la constitución de la identidad y en la memoria (Astvaldsson 1998; Dean 2010; Guffroy 1999; Janusek 2015; Martiarena 2014; Robin 2010; Sillar 2009). La literatura arqueológica reciente las ha concebido, con ciertos matices, como objetos sobre los cuales se orquestaron y objetificaron significados y recuerdos, no solo por su posicionamiento en el espacio, sino también por su uso, reutilización, traducción, reconfiguración e incluso destrucción (Lazzari et al. 2015; Nielsen 2008; Mills 2008). En este sentido, estas esculturas, tanto en lo físico como en lo conceptual, integraron a través del tiempo y el espacio diversos entramados que tuvieron la capacidad de establecer, reproducir y/o alterar relaciones de poder de manera efectiva (Aschero 2007).

\footnotetext{
${ }^{1}$ Centro de Estudios Históricos “Prof. C. Segreti”, CONICET. Universidad Nacional de Córdoba, Córdoba, Argentina. juliansalazar@ffyh.unc.edu.ar

2 Instituto de Humanidades, CONICET. Universidad Nacional de Córdoba, Ciudad Universitaria, Pabellón Agustín Tosco, Córdoba, Argentina. valefrancosalvi@unc.edu.ar
}

Recibido: abril 2019. Aceptado: enero 2020. 
La arqueología de los valles mesotérmicos del Noroeste Argentino (NOA) ha construido diversas narrativas a partir de este tipo de objetos, sobre todo menhires, suplicantes y máscaras, siendo claves en las interpretaciones acerca de las relaciones sociales, la ritualidad y los cambios acaecidos en torno al primer milenio de la Era cristiana (Aschero 2007; García Azcárate 1996; Tartusi y Núñez Regueiro 1993; Pérez Gollán 2000). En general, los análisis se efectuaron con pocas referencias al contexto de hallazgo, sobre todo porque en su mayoría fueron removidas a lo largo del siglo XX, sin la intervención de profesionales ni métodos sistemáticos (Chambeaud 2007).

A fines del siglo XIX y principios del XX, las características excepcionales de estas piezas llamaron la atención de los exploradores y arqueólogos pioneros de la región. Ambrosetti (1897) fue el primero en mencionarlas planteando hipótesis que vinculan a las poblaciones prehispánicas locales del valle de Tafí con las de la cuenca del Titicaca. Pocos años después, justamente en su recorrido por Anfama y La Ciénega, Quiroga (1899) describe detalladamente los menhires que detecta y brinda información del emplazamiento de cada uno. El autor los interpreta como piedras sagradas citando cronistas peruanos que planteaban la idea de que fueron "huacas veneradas". En ese sentido, se obtiene la primera interpretación acerca del rol de estas piedras en el mundo prehispánico de la zona. Posteriormente, Schreiter (1928) resalta la presencia de menhires al sur del valle de Tafí, en el Mollar, y los define como monumentos megalíticos. Al igual que Ambrosetti publicaron planos con su ubicación original lo que constituye un avance importante en la búsqueda de comprender su contexto y rol en el pasado.

Ya en la década de 1960, en el marco del normativismo, las esculturas monolíticas del Valle de Tafí fueron concebidas como uno de los elementos centrales que se utilizaron para vincular a la cultura homónima con las poblaciones altiplánicas de Wankarani e incluso Tiwanaku, esto es, la existencia de influencias circumtiticacas a través de un proceso de difusión progresivo reflejado en las estelas (González 2004:30). Tartusi y Núñez Regueiro (1993), en una propuesta un tanto diferente, interpretaron que los menhires (o "estelas") no podrían haberse manufacturado de manera individual sino que habrían requerido del trabajo colectivo de varias familias y habrían sido destinados a funciones específicamente ceremoniales (Tartusi y Núñez Regueiro 1993). En base a esto y a sus investigaciones en el Alamito, propusieron la existencia de un estadio "cultista", en el cual habrían existido varias jefaturas incipientes no unificadas organizadas sobre la base de múltiples centros ceremoniales. Según los autores, estas estructuras habrían sido legitimadas por la utilización de cierto repertorio ideológico compartido, que a su vez les permitía incluirse en redes de interacción macrorregionales (por ejemplo, la "ruta del cebil" propuesta por Pérez Gollán [1992]). Algunas de estas elites habrían logrado eclipsar progresivamente a los polos locales, bajo la órbita de centros cada vez más influyentes. En efecto, concluyeron que este proceso habría sido lo que desembocó en la Integración Regional, bajo lo que se conoce como Aguada, con centro principal en el valle de Ambato (Núñez Regueiro y Tartusi 2002).

García Azcárate $(1996,2000)$ a través de un análisis integrador en el valle de Tafí (Figura 1) planteó que muchas de estas esculturas se encontraban emplazadas en diferentes contextos espaciales que incluían unidades domésticas, andenerías de cultivo y corrales, en sitios excepcionales y distintivos, en el centro de recintos, en torno a montículos, y en senderos o pasos. La escasa información disponible acerca de los contextos arqueológicos de hallazgo le impedía brindar mayores precisiones, aunque sí pudo reconocer que estas rocas habían interactuado en un paisaje sociopolítico complejo y contingente. En este sentido, la autora relacionó a los monolitos del valle de Tafí con los huanca ${ }^{1}$ descritos a partir de análisis etnográficos por Duviols (1973, 1979), y propuso un abordaje teórico-metodológico novedoso.

En la misma línea, Pérez Gollán (2000) interpretó a las esculturas de "suplicantes" destacando su papel como huancas, punto luego retomado por Aschero (2007) que sostiene que habrían constituido la representación de la potencia de estos ancestros, aunque los denomina "mallqui" por parecerse más a la metáfora visual de un cadáver. Aschero (2007) planteó que para el primer milenio de esta Era ya estaban presentes las máscaras como "huauqui" que acompañaban a los cadáveres, las esculturas de "suplicante" como representantes del "mallqui" (Pérez Gollán 2000) y la de la figura humana "en bloque" como el monolito-huanca que reproducía la potencia fertilizadora del ancestro como marca visible y permanente (Aschero 2007).

Estudios recientes en el área revalidan la idea de que estas estelas habrían sido concebidas como presencias ancestrales que ordenaban el espacio y el tiempo social y que a través de ellas es posible dilucidar arqueológicamente las prácticas de hacer lo ancestral (Lazzari et al. 2015). Los estudios de contextos domésticos en el valle de Tafí, por ejemplo, concluyen que las cistas habrían actuado como seres ancestrales presentes en los patios centrales de los conglomerados residenciales, esto es, en el centro de la vida y la experiencia cotidiana de quienes habitaban las viviendas (Salazar et al. 2011). Al respecto, se registran en las fuentes etnohistóricas algunas menciones sobre la adoración a progenitores cuyos huesos venerados eran guardados en sepulcros de piedra (Duviols 1973).

Nielsen (2008) advierte como se interpreta y asume en la literatura arqueológica la idea de que estos objetos fueron representantes materiales de los antepasados, lo 


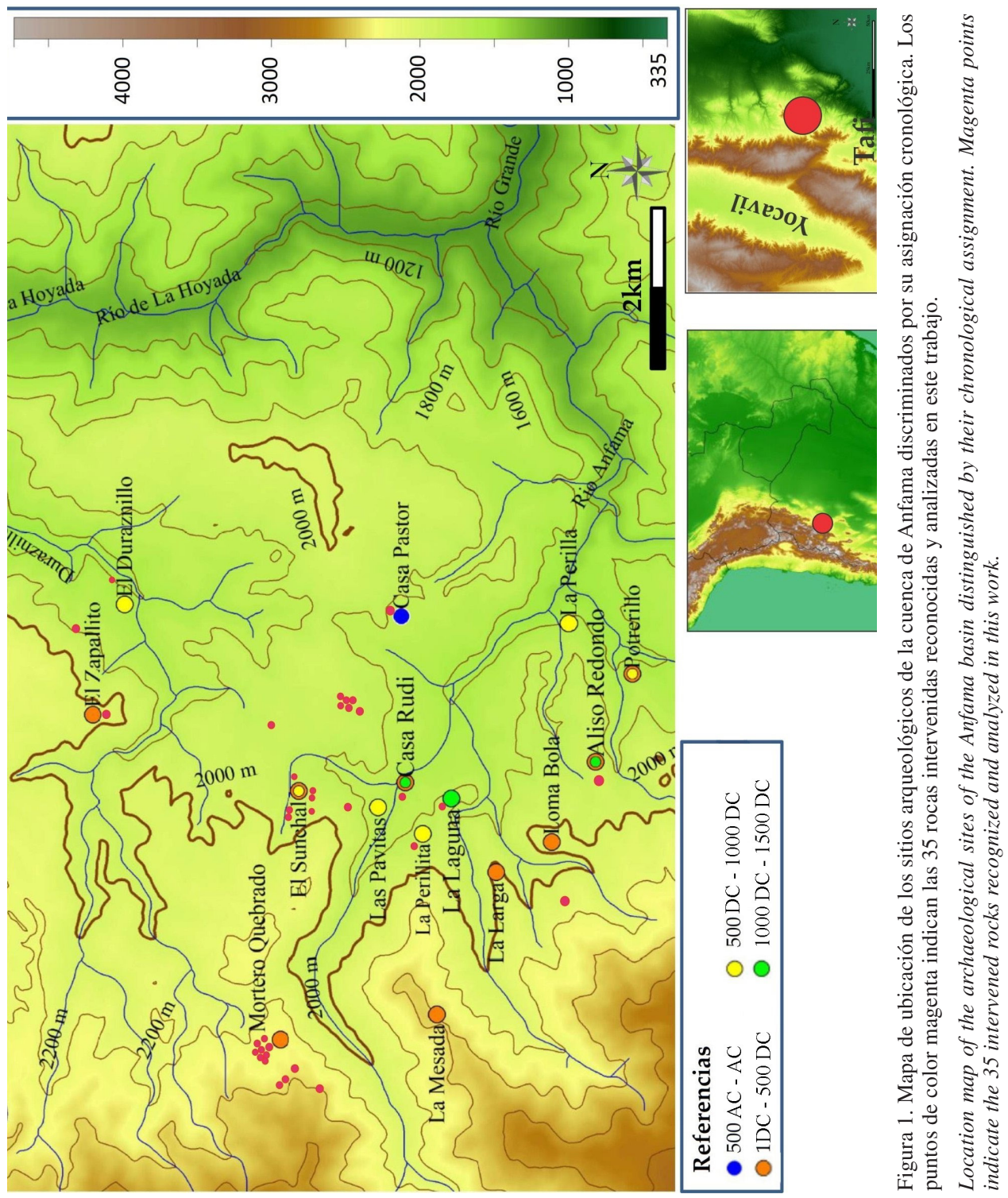


que implicaría en muchos casos, la construcción de un tipo de relación esencialista y universal, que es inmutable en los Andes. En relación a este planteo, podemos señalar que diferentes observaciones etnográficas registran prácticas de sacralización en constante transformación y de interpretación/reinterpretación de estas rocas frente a contingencias cotidianas (Astvaldsson 1998). A su vez, la importancia del monolito no radicaría en relación a una sacralidad trascendente sino en referencia a las cualidades materiales que manifiesta, esto es, color, dureza, rasgos tallados, orígenes no locales y ubicación (Astvaldsson 1998; Janusek 2015). En su defecto, tampoco implicaría la necesidad de imputar cualidades puramente humanas mediante la adición de tratamientos con características faciales para percibir el mundo material como vivo y como sensible (Cobo 1990 citado en Sillar 2015).

A los fines de sumar nuevas visiones acerca del rol de estos objetos en el pasado prehispánico nos propusimos como objetivo central reconceptualizar el papel que desempeña la materialidad en la vida humana en pos de complejizar el entendimiento de como las poblaciones prehispánicas siguieron reglas, valores y comportamientos a través del tiempo (Bourdieu 1977). En este caso particular, el estudio de las rocas se aborda desde una perspectiva relacional (Bourdieu 1977, 2006) que concibe a los materiales como agentes, en una dimensión histórica y en relación contingente con otros seres (Janusek 2015). Entenderlos como materialidad (Meskell 2005; Tilley 2007) nos permite otorgarles un status en la vida social que pone foco en las relaciones más que en las categorías. En este punto creemos que plantear a priori que los monolitos-huancas o ciertos objetos como máscaras de piedra o estatuillas, presentes en el registro arqueológico, cumplieron una función específica (i.e. culto, guardianes y demarcadores territoriales) en eventos puntuales (Berberián y Nielsen 1988; García Azcárate 1996) solo condiciona lo que a nuestro juicio es uno de los aspectos más importantes de este fenómeno, que estas materialidades relacionan múltiples actividades, escenarios y temporalidades de prácticas con una misma forma (Nielsen 2006, 2007).

A partir del hallazgo en contexto de numerosas rocas estilizadas, asociadas a ocupaciones aldeanas del primer milenio de la Era cristiana en la cuenca de Anfama se generaron algunos interrogantes. ¿Cuál es la variabilidad de rocas intervenidas en el caso de estudio? ¿Qué tipo de escenarios recorren estas rocas? ¿Qué interacciones sociales promovieron, habilitaron y condicionaron a través del tiempo? ¿Es posible explicar por qué los pobladores de Anfama intervinieron estas rocas? Con el fin de resolverlos, en este trabajo se consideran distintos tipos de rocas intervenidas desde múltiples variables. Para tal fin se trazó una secuencia de análisis que primero se refirió a una indagación de los aspectos materiales y técnicos de manufactura de estos objetos, seguido por el análisis de la distribución de las esculturas en el territorio y los escenarios referenciados por ellas junto a las relaciones implicadas entre estos objetos y otros seres en toda su trayectoria de vida.

\section{El Mundo de las Piedras en Aldeas, Viviendas y Patios}

Anfama es una cuenca emplazada en la vertiente oriental de las Cumbres Calchaquíes muy próxima al valle de Tafí (Figura 1), pero de difícil acceso para el turismo y la población en general y también para la realización de tareas arqueológicas. Su posicionamiento geográfico posibilitó la conservación de numerosas esculturas líticas en su contexto arqueológico original. A diferencia de lo que se observa en la región, en esta área hemos registrado 35 rocas intervenidas mediante diversas modalidades.

En los últimos años (Salazar et al. 2019) hemos identificado en esta zona una serie de sitios arqueológicos prehispánicos construidos y ocupados desde el $2200 \mathrm{AP}$ hasta el $450 \mathrm{AP}$, es decir desde unos siglos antes de la Era cristiana hasta el siglo XVI aproximadamente. La mayor cantidad de ocupaciones registradas hasta la actualidad corresponden al primer milenio de la Era y constituyen poblados dispersos conformados por unidades residenciales compuestas, notoriamente distanciadas entre sí.

Este periodo en el NOA representa la emergencia y consolidación de asentamientos aldeanos. En distintas zonas, con diversas modalidades, se instalaron ocupaciones relativamente sedentarias a partir de las cuales se intervino activa y sensiblemente en el paisaje, construyendo estructuras residenciales, instalando campos de cultivos, que implicaron remoción de suelos, limpieza de superficies y ejecución de estructuras para el manejo del agua. Estas transformaciones se vieron acompañadas de la emergencia de diversas tecnologías que estructuraron escenarios materiales novedosos que articularon relaciones sociales centradas en la reproducción de las lógicas domésticas.

Las viviendas de este momento en el área de estudio se conforman de varios recintos de planta circular, cuyos muros se definen a partir de lajas clavadas verticalmente, adosados a un patio central de amplias dimensiones. $\mathrm{Si}$ bien no hemos identificado hasta ahora ningún tipo de vestigio asociable a instalaciones productivas agrícolas, las mismas pueden haberse dado en terrazas fluviales y laderas sin uso de estructuras, tal como se observan en la actualidad. En efecto, en el registro arqueológico, además de los numerosos instrumentos de molienda y vasijas de cerámica, se han identificado evidencias arqueobotánicas de maíz y zapallo (Salazar y Molar 2017) que demuestran el procesamiento y consumo de productos agrícolas.

En este trabajo denominamos "rocas intervenidas" a todas aquellas piedras que presentan modificaciones, 
en su forma base o en sus superficies, por grabado, esculpido, percusión y/o pulido, generando formas y/o superficies estilizadas. El conjunto analizado fue identificado, en su mayoría, a través de estudios sistemáticos en la cuenca del río Anfama, mientras que en unos pocos casos fueron recolectadas por comuneros/as locales y permanecen en su poder. En esta microregión venimos desarrollando un plan de trabajo que ha incluido prospecciones sistemáticas de estructuras y rasgos en superficie, relevamientos y confección de planimetrías arqueológicas. La identificación de una gran variedad de sitios llevó a realizar un muestreo, a partir del cual se realizaron sondeos exploratorios en 10 ocupaciones y excavaciones en área en tres de ellas. Los análisis contextuales fueron enriquecidos a través de matrices de Harris, a los fines de reconocer las relaciones estratigráficas de los contextos en los que estuvieron interactuando, y de ortofotografías y reconstrucciones tridimensionales fotogramétricas de las excavaciones arqueológicas.

Determinadas unidades estratigráficas pudieron ser fechadas e incluidas en una secuencia cronológica general. La conjunción de estas técnicas permitió aproximarnos a la discusión del rol de estos objetos en la vida diaria en Anfama y en definitiva, introducirnos en la caracterización de la diversidad de piezas registradas definiendo sus contextos de hallazgo, así como su asociación a otros rasgos para discutir su intervención en la construcción de relaciones sociales y en la configuración de las sociedades aldeanas.

En las prospecciones y excavaciones efectuadas hemos identificado 35 rocas intervenidas en diferentes sectores y contextos (Tabla 1), muchas de ellas $(n=10)$ son bloques de distintos tamaños con pequeñas cavidades hemisféricas grabadas. Estas últimas se disponen en grupos, formando dameros, líneas, u otros conjuntos. Un alto porcentaje $(n=15)$ constituyen bloques tallados, pulidos y grabados que podrían asociarse a las piezas tradicionalmente englobadas en la categoría de menhir-huanca. Los hallazgos más relevantes para la problemática planteada se diferenciaron en los sitios Mortero Quebrado ( $\mathrm{n}=12)$, El Sunchal ( $\mathrm{n}=6)$ y La Perillita $(\mathrm{n}=1)$ donde se efectuaron excavaciones arqueológicas sistemáticas y se plantearon las principales hipótesis acerca de las dinámicas de ocupación. El resto de las piezas $(\mathrm{n}=16)$ se recuperaron dispersas en distintos sectores de la cuenca, tal como se indica en la Figura 1.

Mortero Quebrado (MQ) es un asentamiento constituido por siete unidades residenciales, emplazado en un sector de cumbre a $2.400 \mathrm{msm}$ (Figura 2). Los conjuntos arquitectónicos, distanciados entre sí por más de $100 \mathrm{~m}$, se componen de múltiples habitaciones circulares o subcirculares adosadas a amplios patios, que se posicionan como el centro articulador del espacio en la edificación. Los muros están construidos con lajas de gran tamaño clavadas en los pisos con su eje mayor en posición vertical. Para la confección de estos últimos se aprovechó la roca madre local, una arenisca muy blanda que en ocasiones fue formatizada buscando regularidad o excavada configurando rasgos subsuperficiales para almacenaje, inhumaciones o para colocar los postes que sostenían las techumbres. Las irregularidades mayores de esta roca se salvaron en algunos casos a través de la instalación de tapas de lajas.

Los controles estratigráficos de las excavaciones realizadas hasta ahora en tres de esas unidades, evidencian una sola ocupación que habría finalizado con un abandono planificado. Los fechados radiocarbónicos realizados en las unidades U2 y U5 datan esa ocupación en los primeros siglos de la Era cristiana, entre cal. 126 DC y cal. 434 DC (Salazar et al. 2019).

En este sitio se identificaron 12 rocas intervenidas (Tabla 1): una zoomorfa -tipo 3- que representaría un camélido asociada a un muro de la U5; una fálica -tipo 1-, en el sector extramuros de la U3; un bloque tabular tipo 5 con un motivo antropomorfo (mascariforme) doble sobre el cual se ejecutó otro motivo doble ornitomorfo antropomorfizado, en el piso del recinto central de $\mathrm{U} 4$, y 5 bloques con conjuntos de pequeñas cavidades hemiesféricas -tipo 2, 4 y 5-, 4 grabados marginales y tallas en bulto fracturadas en el proceso de producción, procedentes de los muros y derrumbes de un recinto adosado de la U2 -tipo 2, 5 y 1 -.

El Sunchal (ES) es un sitio constituido por distintas ocupaciones domésticas superpuestas emplazadas en una terraza fluvial a $1.900 \mathrm{msm}$. Si bien en superficie no se observaban claramente estructuras o rasgos arquitectónicos, la excavación de casi $70 \mathrm{~m}^{2}$ distribuidos en varios sondeos puntuales y dos áreas más amplias, permitió establecer la existencia de numerosos elementos constructivos y depósitos, cuya secuencia depositacional fue interpretada mediante una matriz de Harris (1991) en la que se definieron al menos dos fases de ocupación.

En la más temprana se observa una estructura constituida por relictos de un sólido muro de rocas que formaría un amplio recinto circular (probablemente un patio central), al cual se adosa otro menor construido a partir de lajas clavadas. El conjunto artefactual está constituido fundamentalmente por fragmentos de cerámica ordinaria asignables al primer milenio de la Era cristiana en la región (Franco 2019). Esta primera ocupación fue datada entre cal. 46 AC y 63 DC y cal. 332 DC y 420 DC (Salazar et al 2019); la misma sufrió una gran alteración que es posible observar en una interfaz de destrucción, sobre la cual se construyó otro recinto de distintas características, de muros lineales y terminación informal. El piso ocupacional asociado, sobre el cual se identificó un considerable conjunto de cerámicas del 


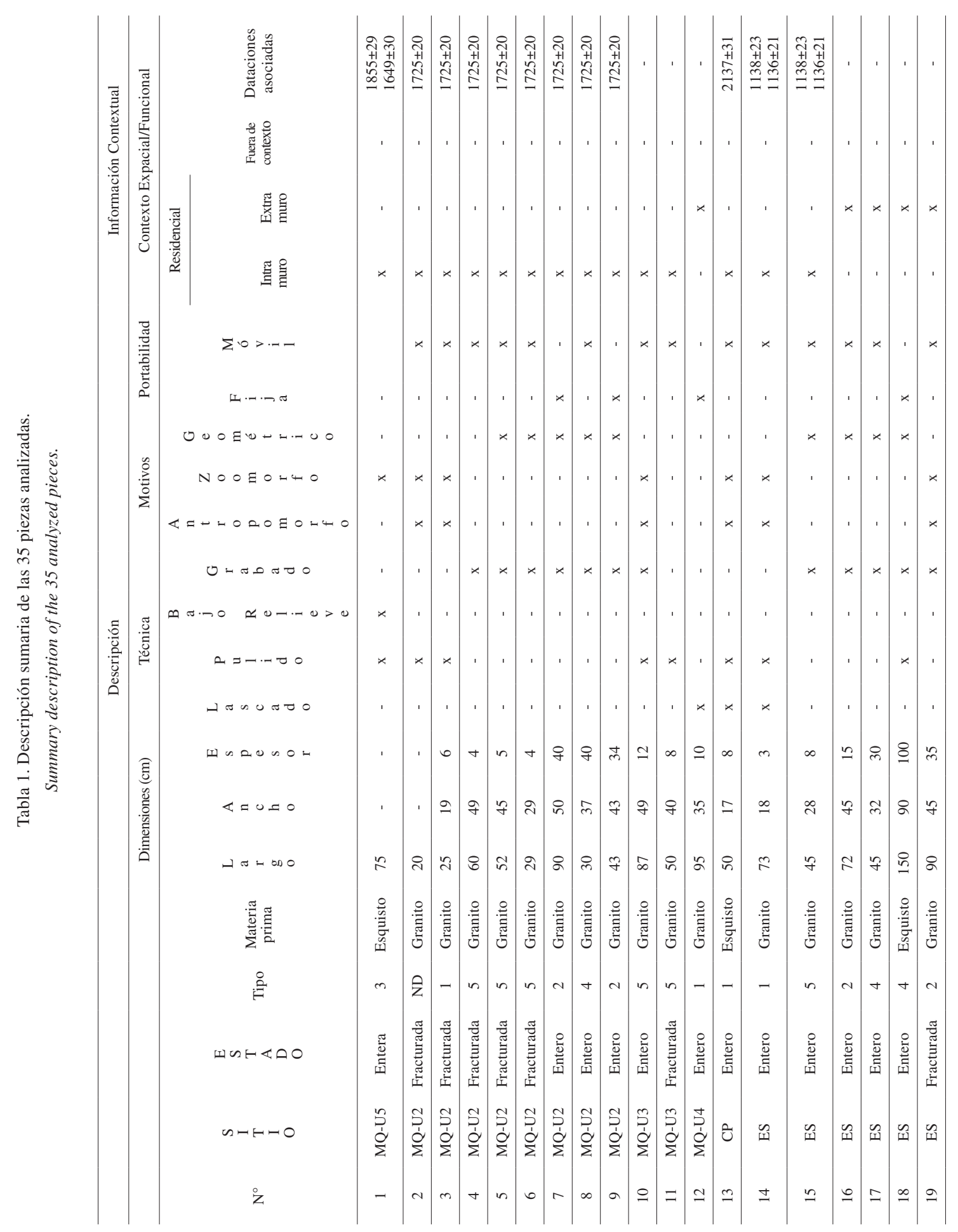




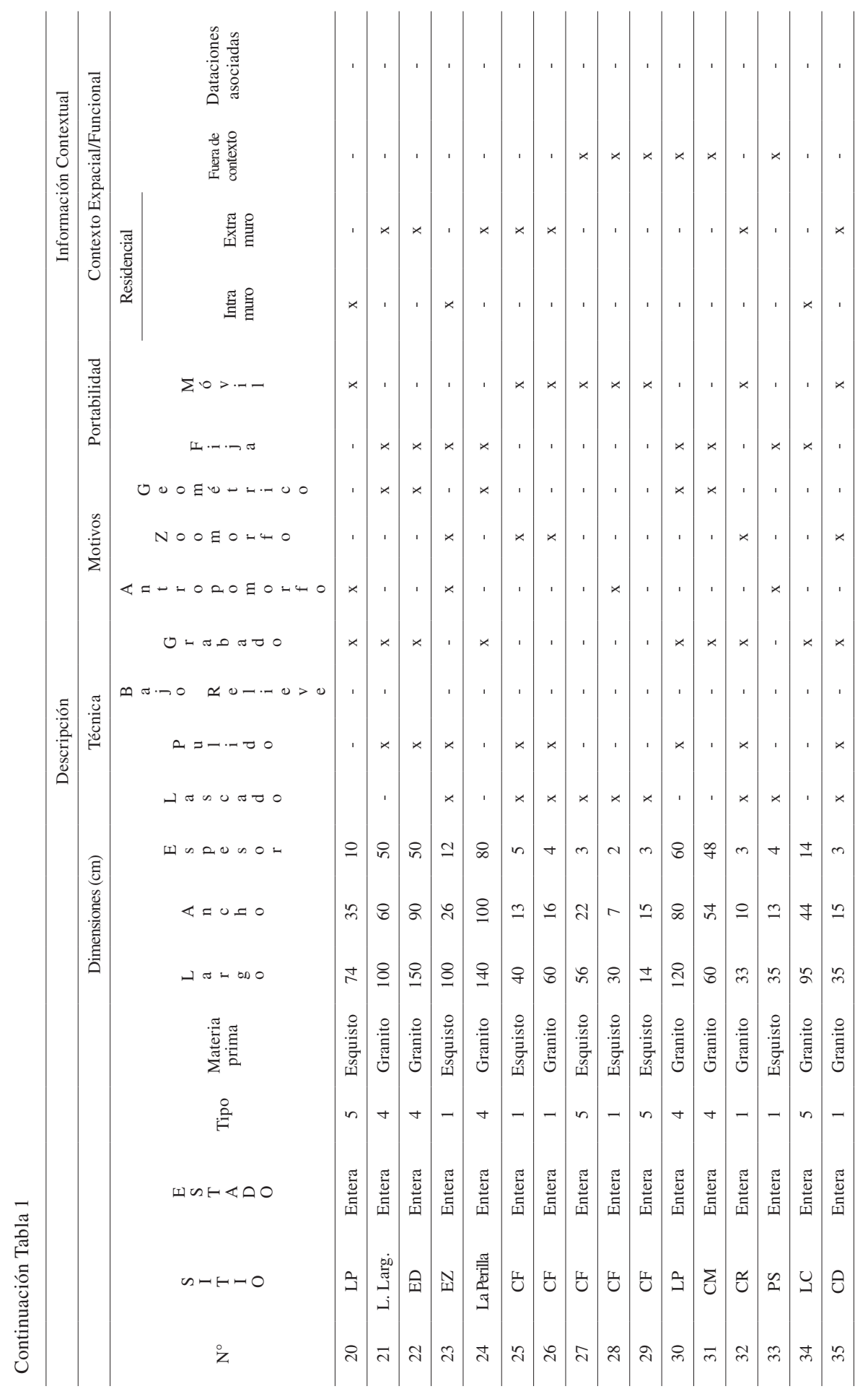




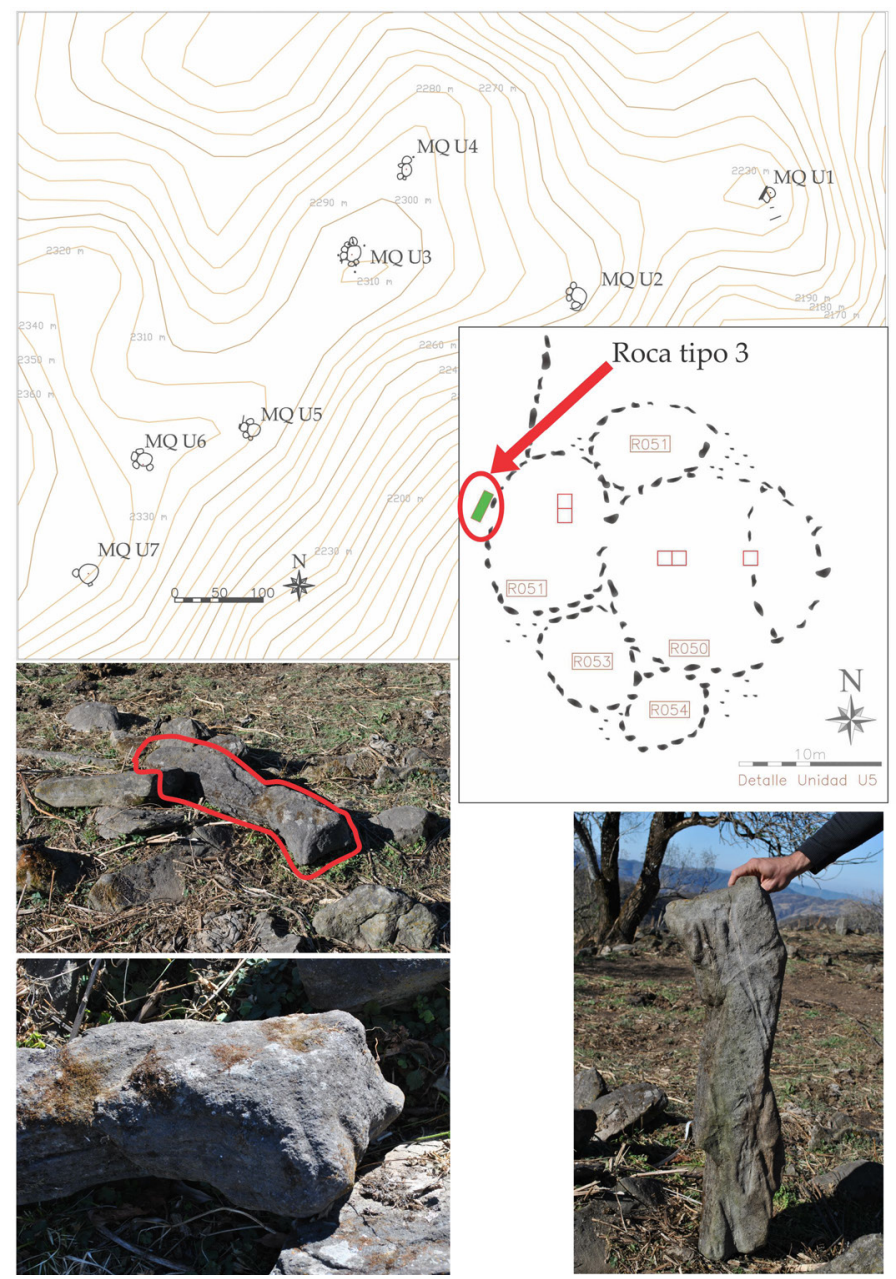

Figura 2. Plano de planta de Mortero Quebrado (MQ) con detalle de la unidad U5. Puede observarse el lugar de hallazgo de la roca intervenida (del tipo 3), una vista de la cabeza de camélido, esculpida en su extremo superior y una vista lateral, en la cual se denota la particular forma natural de la roca y su fusión con la forma intervenida antrópicamente.

Floor plan of Mortero Quebrado $(M Q)$ with detail of the unit U5. Note the location of the intervened rock (type 3), a view of the camelid head sculpted at its upper end, and a side view, which shows the particular natural shape of the rock and its fusion with the anthropically intervened form.

primer milenio pero con la incorporación de grupos de superficies alisadas por peinados gruesos (Franco 2019), fue datado en cal. 770 y 990 DC (Salazar et al 2019). En estratos superiores, sin asociación a ninguno de estos dos componentes, ni a otros rasgos o conjuntos materiales datables, se identificaron fragmentos de cerámica Santamariana bicolor y de Famabalasto negro inciso. Por último, sobre este espacio, se dispuso una instalación subactual destinada a la agricultura y ganadería que funcionó hasta hace unas décadas alterando los estratos superficiales del sitio.
En el sitio se identificaron seis rocas con rastros de intervención: una fálica -tipo 1-y una tabular con cavidades hemiesféricas -tipo 5-; un bloque elongado con una cara completamente cubierta de cavidades similares de variados tamaños que en principio imitaría las manchas oceladas de un felino -tipo 2-, un bloque tabular con decoraciones similares -tipo 4-, un gran bloque elongado con un diseño de dos circunferencias concéntricas en cuyo interior se presentan tres cavidades también hemiesféricas -tipo 2- y un bloque fijo con la misma intervención -tipo 4- (Figura 3). 


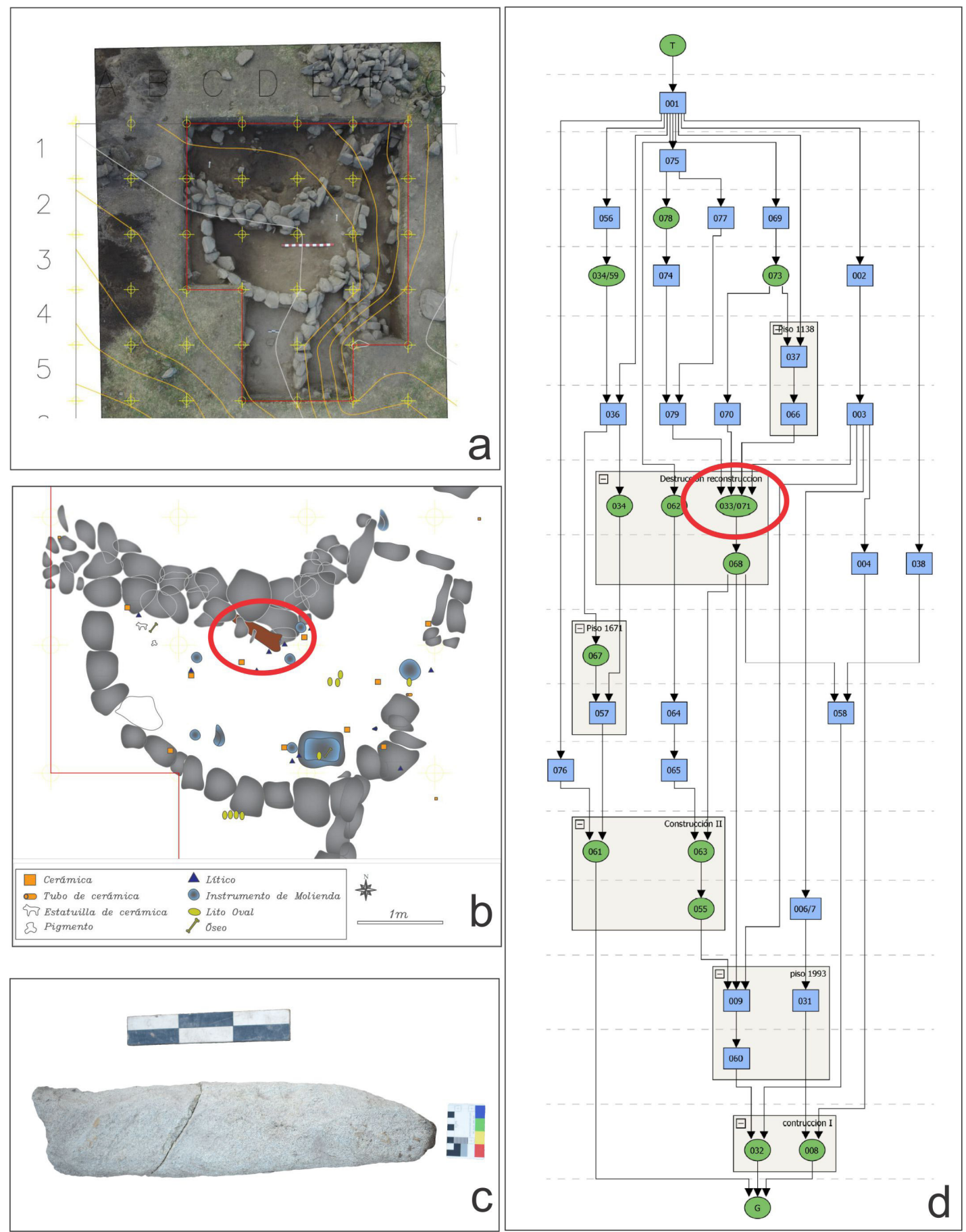

Figura 3. Roca tipo 1, y su contexto de hallazgo. a. Vista general de la excavación de El Sunchal (ES). b. Planta de un sector de la excavación donde se observa el piso ocupacional temprano (UE 009) y el muro (UE 033/071) que se le superpuso después de su parcial destrucción dentro del cual se halló la roca intervenida (demarcada con un círculo rojo). c. Vista frontal de roca intervenida. d. Matriz de Harris que sintetiza la superposición de eventos registrados. Se demarca con un círculo rojo la UE 033/071 donde se dio el hallazgo de la pieza.

Rock type 1 and its discovery context. a. General view of the El Sunchal (ES) excavation. b. Plant of an excavation sector with the early occupational floor (UE 009) and the wall (UE 033/071), that was superimposed after being partially destroyed, within which the intervened rock was found (demarcated with a red circle). $c$. Front view of intervened rock. $d$. Harris matrix that synthesizes the superposition of recorded events. The EU 033/071, where the piece was found, is marked with a red circle. 
Finalmente, en la zonas de cumbres $(1.850 \mathrm{msm})$ se encuentra el sitio La Perillita (LP). En esta instalación se identificaron tres unidades arquitectónicas en su mayoría constituidas por recintos subrectangulares grandes y pequeñas estructuras circulares, cuyos muros presentaban un mal estado de conservación (Figura 4). Si bien en las excavaciones realizadas no se pudieron exponer claramente muros, se registró una gran cantidad de bloques tabulares muy delgados (no más de $0,10 \mathrm{~m}$ de espesor), alargados (promedio de $0,70 \mathrm{~m}$ de largo y 0,40 m de ancho), los cuales se encontraban caídos sobre otras rocas o sobre los sedimentos, alineados entre sí. Esto lleva a pensar que los mismos se habrían clavado en el piso, para conformar la cara externa del muro y darle uniformidad. Esta técnica constructiva, sin embargo, no habría otorgado una gran solidez al muro, el cual se habría derrumbado. Si bien no pudimos realizar ninguna datación en esta instalación, las características estilísticas de los conjuntos cerámicos recuperados y de la arquitectura (Salazar et al. 2019) permiten proponer que se habría ocupado principalmente en la segunda mitad del primer milenio DC. En una de las paredes del recinto 27 fue hallada una roca tabular (del tipo 5) con un grabado mascariforme que por su posición corresponde a un proceso de reclamación (Figura 4).

\section{Una Primera Aproximación al Estudio de Rocas Intervenidas en Anfama}

\section{Aspectos técnicos de manufactura}

El estudio de la fisicalidad de estos objetos buscó identificar en primer lugar la materia prima, su disponibilidad en el área y el contexto medioambiental. A su vez, esto implicó no solo indagar en las fuentes de materias primas y su accesibilidad sino también interpretar qué relaciones se vieron involucradas en este proceso tanto con el ambiente como con otros seres. Siguiendo la lógica general de biografía de estos objetos, continuamos en la indagación acerca de los aspectos técnicos de la manufactura con un análisis tipológico de las formas bases de la pieza, seguido por
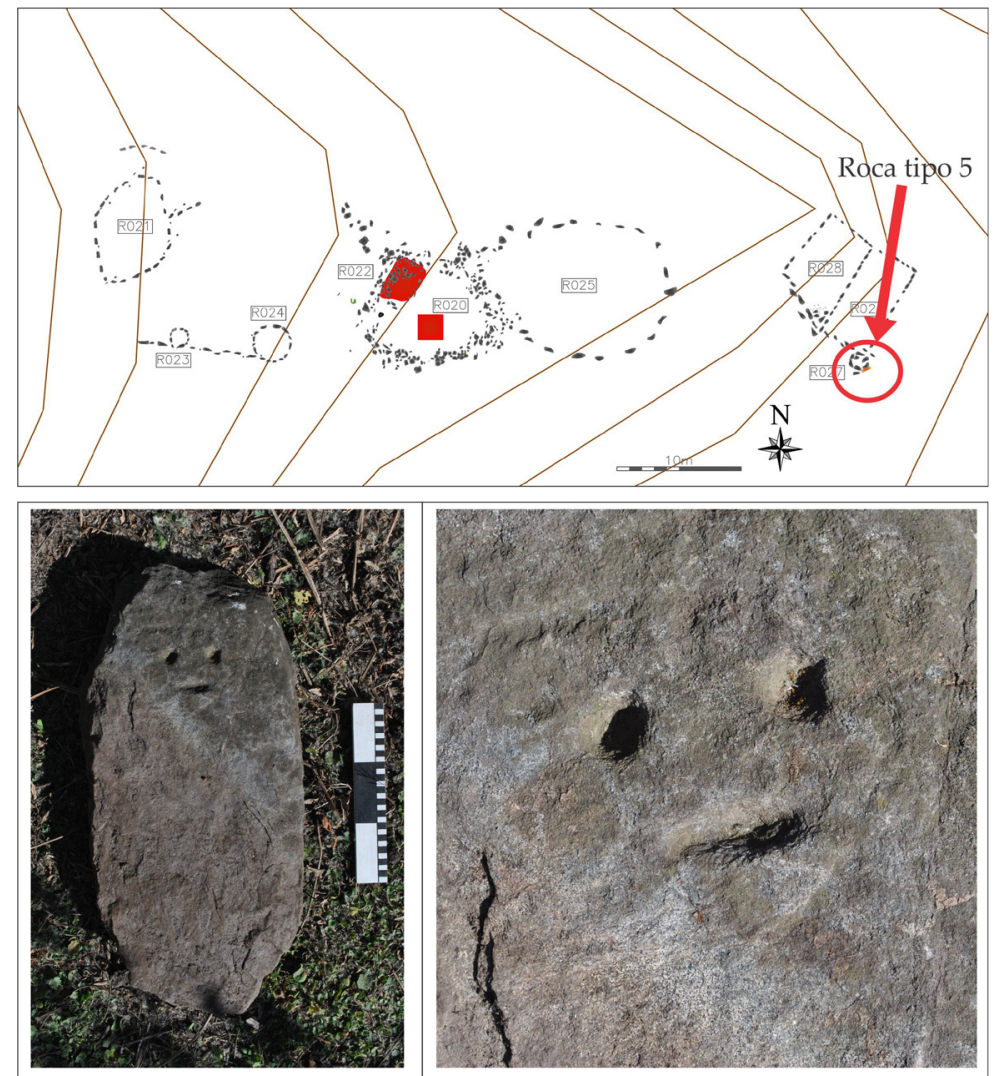

Figura 4. Plano de Planta de Sitio La Perillita (LP), con localización de hallazgo de roca tabular (del tipo 5) con un grabado mascariforme. Vista frontal de la pieza y detalle del motivo.

Floor plan of the La Perillita (LP) site, with the location of a tabular rock (type 5) with a mascariform engraving. Front view of the piece and detail of the motif. 
una descripción sumaría a fin de registrar variables de identificación, procedencia (p.ej., posición del hallazgo, descarte), estado (p.ej., alteraciones naturales como lustres, pátinas, estrías, etc.) y dimensiones (p.ej., ancho máximo, longitud, etc.) (Aschero 1975, 1983).

El análisis tecno-morfológico de las esculturas implicó el relevamiento de variables que incluyeron estado de la muestra (entera/fracturada), forma base, materia prima, tamaño, técnica, motivos y portabilidad. En referencia a las fracturas, se determinaron los tipos a nivel macroscópico (transversal u ortogonal, plana oblicua, en ángulo, etc.). Finalmente, los diseños iconográficos registrados en las piezas fueron comparados con los registrados en el valle de Tafí y Cumbres Calchaquíes tanto en el arte rupestre como en esculturas, y a partir de esta información fue posible inferir aspectos estilísticos, cronológicos y contextuales (Aschero 2007; Berberián y Nielsen 1988; García Azcárate 1996; Lazzari et al. 2015).

A partir de la existencia o no de formatización y los atributos morfológicos de la forma base de la pieza clasificamos la diversidad de especímenes registrados a través de una tipología (Figura 5). El tipo 1 corresponde a piezas formatizadas y se caracteriza por presentar en su vista frontal un sector de gran espesor que se reduce abruptamente en la sección media-superior. Ambas partes pueden o no estar separadas por una acanaladura transversal al eje mayor de la pieza. La parte inferior es de forma rectangular con lados planos. La forma de la base es trapezoidal con lados no paralelos de medidas muy similares. El tipo 2 también formatizado presenta una base más ancha a la parte superior de la pieza, sin aristas demarcadas y tanto en el lado frontal como sagital se destaca un contorno similar, esto es, base ancha que de forma progresiva disminuye su diámetro en la parte superior. El tipo 3 se define por presentar en la parte superior de la pieza un tallado en sus tres dimensiones y exhibir en su base forma rectangular con lados planos. Su forma base no presenta formatización $\mathrm{y}$ al igual que el tipo 4 y 5 se seleccionan por sus formas naturales ya aptas para su utilización. El tipo 4 presenta un contorno hexagonal con bordes suaves. El tipo 5 presenta un contorno cuadrangular, bordes suaves y una base levemente más ancha que la parte superior, la forma de la base es rectangular.

La construcción de esta tipología centrada en morfologías, así como características estilísticas visuales es solo un instrumento orientado a describir la

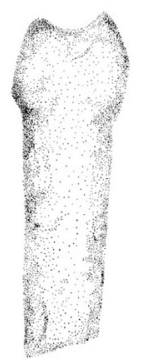

Tipo 1

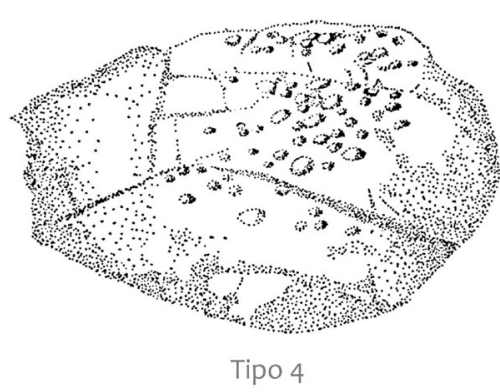

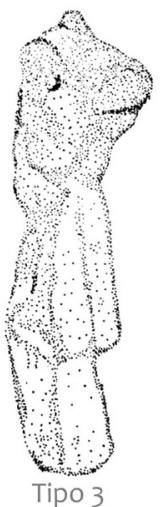

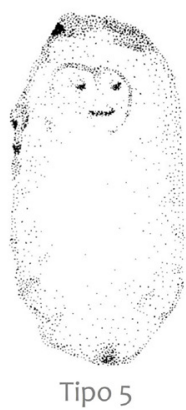

Figura 5. Tipología de morfología de formas bases de las rocas intervenidas.

Typology of morphology of base forms of the intervened rocks. 
variabilidaddel conjuntoperonoimplicalaidentificación entre la roca y la entidad no pétrea corporizada en ella. Diversos casos etnohistóricos muestran que numerosos pueblos andinos, especialmente los incas, no necesitaban de la semejanza para establecer identidad, sino que eran las características transubstanciales recordadas y transmitidas a través de la práctica y la cultura oral los que posibilitaron la corporización de de determinadas entidades en las rocas (Dean 2010). Esta modalidad de relación previene a la interpretación de las entidades hechas piedra y refuerza la necesidad de análisis contextual de prácticas y de los escenarios materiales de los cuales los mismos formaron parte.

Las materias primas empleadas se corresponden por sus características macroscópicas con rocas metamórficas -esquistos micáceos y graníticos² - (Toselli et al. 2003) disponibles en la misma localidad en fuentes secundarias (p.ej., depósitos fluviales). La selección de las rocas está íntimamente vinculada con la morfología y textura que se buscaba representar. No se reconocieron materias primas alóctonas. En el caso de la roca zoomorfa que representa a un camélido (tipo 3) asociada a un muro de la U5 en MQ (Figura 2), por ejemplo, se seleccionó un bloque muy particular, estrecho y alargado, de morfología poliédrica irregular en zig-zag. En otros casos se aprovecharon bloques prismáticos con superficies planas para ejecutar los grabados de manera sencilla, especialmente en el tipo 5, como es el caso del bloque decorado con aplicación mascariforme hallado en el sitio LP (Figura 4).

Se advierte, sin embargo, que en numerosos casos el traslado de las rocas implicó cierta logística, por ejemplo, el acarreo de bloques a sectores de mayor altitud como sucedió en el sitio MQ. El cauce más próximo corre a una distancia de 500 metros aproximadamente pero es de difícil acceso por el desnivel que hay que atravesar para llegar -acumula unos 500 metros aproximadamenteEsto significaría un esfuerzo de logística que incluyó recorrer pendientes pronunciadas de más del $45 \%$.

Los tipos 1 y 2 fueron formatizadas mediante talla de aristas marginales aunque también se registran casos -tipos 3, 4 y 5-donde se aprovecharon los bloques que de forma natural presentaban las características deseadas, como por ejemplo, caras planas y formas tabulares. En ese sentido, aquellas que fueron previamente manufacturadas, se les aplicó la técnica por percusión utilizando instrumentos de mayor dureza con el fin de fracturar y reducir la masa de piedra y darle forma. El desbaste habría resultado del lascado por percusión directa o con dos elementos, en donde el percutor golpea directamente sobre la superficie de la materia trabajada (Babot 2004). Numerosos nódulos esféricos de cuarcita fueron localizados en pisos ocupacionales tempranos de los sitios MQ y ES. Sospechamos que se habrían empleado como martillos o percutores si se consideran los esquirlamientos sobre una gran proporción de su superficie o fracturas generadas por la percusión sobre otro elemento (Figura 6a).

Se diferenciaron trabajos de talla, pulido y grabado que definen morfologías afines a formas fálicas o cabezas de animales. Los diseños iconográficos ejecutados sobre la pieza presentan similitudes con las registradas en el valle de Tafí, esto es, categorías de motivos que se agrupan en mascariformes, geométricos, zoomorfos, y zoo-antropomorfo(GarcíaAzcárate 1996). Sin embargo, es relevante remarcar la variabilidad de las relaciones de semejanza entre las características visuales de las rocas y las entidades no pétreas corporizadas en ellas que complejizan su interpretación (Dean 2010). El grabado (registrado en 21 piezas) fue la técnica más
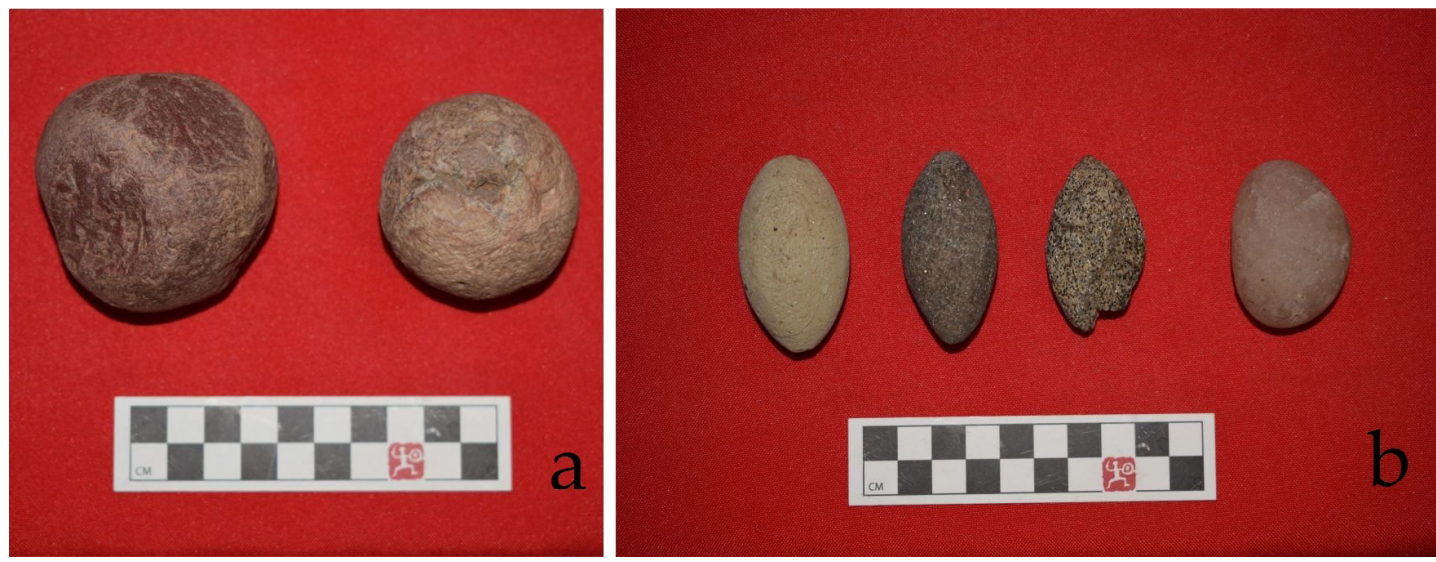

Figura 6. Instrumentos asociados a la percusión y el grabado. A. Nódulo de cuarcita con marcas de golpes y esquirlamientos de Mortero Quebrado (MQ). B. Piedras ovoidales sobre el piso ocupacional temprano de El Sunchal (ES).

Instruments associated with percussion and engraving. A. Quartzite nodule with knapping and splinting marks of Mortero Quebrado (MQ). B. Ovoidal stones on the early occupational floor of El Sunchal (ES). 
utilizada, seguida por el pulido (16) y el lascado (12). Se han identificado pequeñas rocas abradidas y en algunos casos con superficies pulidas con un diseño oval que podría interpretarse como una piedra de honda, pero que por su morfología habría también funcionado como un instrumento útil para generar las cavidades hemiesféricas que se repiten en el registro (Figura 4b). En los pisos tempranos (UE 009 y UE 004) del sitio ES se registraron dos conjuntos de estos instrumentos, uno de tres y otro de cuatro especímenes, sumados a otros dos depositados individualmente, los cuales debido a su posición posiblemente fueron guardados en algún tipo de contenedor de materiales perecederos. En el MQ también se han recuperado instrumentos de este tipo asociados cronológicamente a los primeros siglos de la Era.

Los motivos antropomorfos registrados se reducen a mascariforme y fálico. En el sitio La Perillita se detectó una pieza del tipo 5 con un motivo mascariforme ejecutado mediante grabados (Figura 4). La escultura presenta dos cavidades hemiesféricas a modo de ojos, una cavidad alargada a modo de boca y una demarcación muy leve del contorno de la cabeza, de forma circular o acorazonado, con una acanaladura vertical en el medio de los ojos. El mismo motivo, ejecutado por duplicado sobre un gran bloque del tipo 1 , fue hallado en la unidad U4 de MQ.
Si bien no se registran antropo-geométricos (García Azcárate 1996), sí abundan los zoo-antropomorfos, sobre todo representando la relación falo-felino (González y Núñez 1960) que queda materializada en la morfología del tipo 1 (Figura 5). Los bloques (de granito o esquistos) tallados en sus aristas presentan un cuerpo alargado que se adelgaza hacia su extremo inferior. En el superior se reconoce la cabeza, demarcada ya sea por una acanaladura horizontal o por un ensanchamiento notable, con una gran acanaladura frontal profunda que conforma un falo humano y a la vez la representación de orejas felínicas (Figura 7b y 7c). Este diseño, es muy frecuente (11 en total), presentándose en ES, MQ, El Zapallito (EZ), Casa Rudi (CR), Casa Pastor (CP), Casa Flora (CF), y retoma la decoración, aunque en dimensiones menores, de numerosos monolitos ya registrados en el valle de Tafí (González y Núñez Regueiro 1960). Similar reminiscencia a elementos felínicos puede encontrarse en algunos conjuntos de cavidades hemiesféricas que cubren bloques como el de tipo 2, graficado en la Figura 5.

Entre los zoomorfos, el motivo camélido es escaso, presentándose solo en un caso excepcional por sus características estéticas y por constituir una talla en busto en el sitio MQ (Figura 2). Finalmente, en un solo caso se identificó un diseño doble ornitomorfo, ejecutado

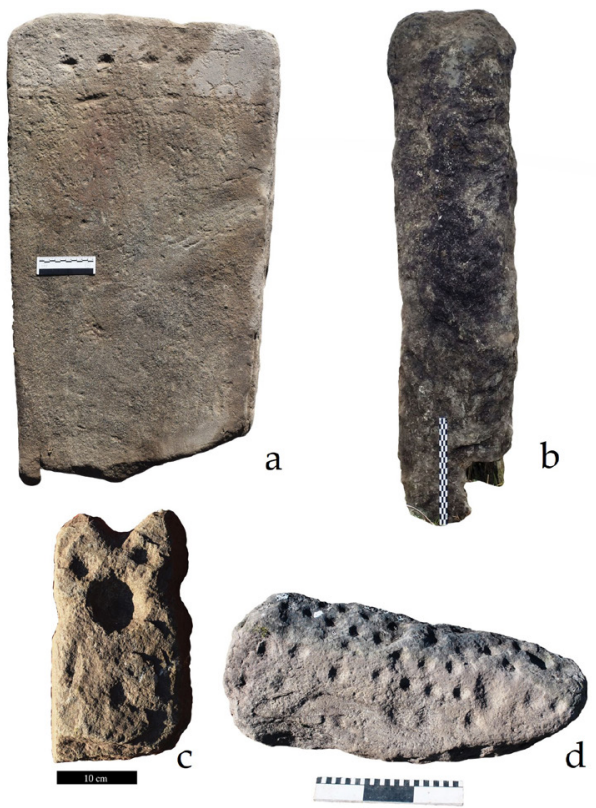

Figura 7. Sección superior: Izquierda, roca tipo 5 con motivo mascariforme y cóndores superpuestos (unidad U4 de MQ). Derecha, roca tipo 1 del sitio EZ. Sección inferior: Izquierda, roca tipo 1 fracturada con motivo mascariforme, hallada por la familia Díaz. Derecha, roca tipo 2 detectada en una pirca subactual en el sitio El Sunchal (ES).

Upper section: Left, rock type 5 with mascariform motif and overlapping condors (unit U4 of $M Q$ ). Right, rock type 1 of El Zapallito (EZ) site. Lower section: Left, fractured type 1 rock with mascariform motif, found by the Diaz family. Right, type 2 rock detected in a subactual pirca on the El Sunchal (ES) site. 
mediante un grabado muy superficial y líneas finas, que puede haber delineado a una pareja de cóndores.

Resulta válido recalcar que abundan los motivos geométricos (en 14 casos) que abarcan cavidades hemiesféricas de 3 a $5 \mathrm{~cm}$ de diámetro, que se presentan aisladas o agrupadas y frecuentemente alineadas.

\section{Escenarios de actividades}

Los distintos elementos materiales (fijos, semifijos y móviles) que constituyen los escenarios sociales e intervienen de manera activa en las actividades humanas no pueden entenderse de manera aislada sino integrados en sistemas continuos (Rapoport 1990). Más aún, la manera en que las rocas se relacionan con prácticas, creencias y estructuras sociales y políticas del mundo andino (Dean 2010) obliga a analizarlas en relación a sus entornos. Las piezas identificadas se pudieron vincular con diversas situaciones de depositación, principalmente relacionados a lugares de realización de actividades domésticas.

Las viviendas construidas y habitadas durante los primeros siglos de la Era cristiana en Anfama y áreas aledañas, constituyen estructuras complejas, que vinculan recintos circulares de diversas dimensiones, en los que se realizan actividades específicas, a patios amplios, que son los ejes articuladores del funcionamiento de todo el conjunto, dan acceso desde el exterior y a su vez dominan la circulación hacia el resto de las habitaciones, y contienen algunos rasgos especiales que hacen a la reproducción de las estructuras de parentesco (Oliszewski 2018; Salazar 2011). De las 35 rocas intervenidas, $17 \mathrm{se}$ han hallado en diversos espacios de las viviendas donde se realizaron distintos tipos de actividades, se depositaron variados conjuntos de materiales y se generaron disímiles situaciones de experimentación.

\section{Pisos ocupacionales de recintos adosados}

La excavación del R34 de la unidad U2 de MQ permitió identificar cuatro rocas intervenidas en contexto. El recinto de planta circular adosado al patio fue interpretado como un espacio de procesamiento final y cocción de alimentos, en el cual se habrían dado algunas tareas de producción artesanal. Su piso ocupacional fue datado en Cal. 252 DC a 384 DC (Salazar et al. 2019). Dos de las cuatro piezas halladas corresponden al tipo 5 , una al tipo 1 y la restante al tipo 2 . En su totalidad se hallaron fracturadas y en etapas iniciales de manufactura, tanto en su formatización por lascado como en momentos de pulimento de superficies. Este dato se vuelve relevante si pensamos que sería uno de los pocos lugares que evidencia restos de este tipo de rocas fracturadas en etapas de manufactura, la cual se daría en el interior de los recintos residenciales. A estas evidencias podemos sumar la presencia de numerosos nódulos de cuarcita roja con marcas de pulimento, esquirlamientos y evidencias de percusión (Figura 6). Los cuatro casos se recuperaron entre los bloques de derrumbes que se depositaron sobre el piso de forma aleatoria.

\section{Pisos ocupacionales de patios centrales}

La excavación del patio de la unidad U4 de MQ permitió identificar un bloque del tipo 5. Esta roca presenta un volumen y ciertos atributos que la hacen de baja portabilidad, lo que limita la movilidad dentro del recinto. La pieza es particularmente destacable debido a que presenta al menos dos eventos decorativos superpuestos. El sustrato original se caracteriza por una doble representación antropomorfa, mascariforme (García Azcárate 1996), ejecutada con grabados muy simples y profundos, con un gesto técnico muy similar al del resto de las rocas descritas en este trabajo. Sin embargo, por encima de este motivo se observa otro par, mucho más complejo, que representa motivos ornitomorfos; fue ejecutado con otra técnica de grabado, solo registrada en este caso, que solo removió una capa muy superficial de material (Figura 7a). Si bien esta roca se halló depositada con su cara decorada hacia abajo, pensamos que habría estado expuesta, quizás formando parte de los muros. Su visibilidad habría sido alta e incluso la superposición intencional de los diseños permite proponer que habría tenido gran relevancia para los observadores de distintos momentos de la ocupación.

\section{Muros}

En los muros se han reconocido diversas formas de integración. Por un lado encontramos bloques grabados, especialmente con cavidades hemiesféricas, que corresponden al tipo 5, como en las unidades U2 y U3 de MQ y en el recinto R2 de ES. Las cavidades se encuentran de a pares o alineadas. Estas representaciones, ubicadas en los lienzos interiores de los muros, parecen ir marcando los lugares habitados para ser experimentados exclusivamente por quienes llevan su vida diaria dentro de las viviendas. Actualmente estos elementos son casi imperceptibles durante todo el día, excepto en aquellos momentos en los cuales la inclinación solar los destaca sobre la superficie de la roca. Sin embargo de haber sido techados los espacios en cuestión, no habrían sido visibles sin la proyección de luz artificial.

Por otra parte, encontramos representaciones que parecen haber estado montadas sobre los muros, pero que pertenecen a los tipos 2 y 3 , en casos como la unidad U5 de MQ (Figura 2), la unidad U2 de La Perillita (Figura 4) y la unidad U2 de ES ${ }^{3}$. Las mismas presentan dimensiones y morfologías altamente visibles desde el exterior demarcando el lugar y referenciando a diversos 
seres a través de motivos antropomorfos, zoomorfos y geométricos.

Finalmente, se observan algunas piezas formando parte de muros pero como reclamaciones, es decir la reincorporación del objeto al contexto sistémico con relaciones funcionales y de significados diferentes. Esto es especialmente observable en el caso de ES donde dos piezas, una del tipo 1, es decir fálica, y otra del tipo 5 fueron incluidas como bloques constructivos en un muro (UE 033), correspondiente a momentos posteriores a la ocupación inicial, que delimita una estructura de finales del primer milenio (Figura 3). Su posición dentro del muro, la cual ocultaba sus características visuales para convertirla en un bloque más de la construcción, hace pensar en dicho proceso. Posiblemente estas fueron obtenidas en la estructura más temprana.

\section{Sectores extramuros}

Si bien nuestras excavaciones se han orientado preferentemente a sectores intramuros, se ha observado una pieza, del tipo 1, en espacios próximos a la unidad U3 de MQ. Allí en una explanada exterior a la estructura se identificó una pieza de unos $0,80 \mathrm{~m}$ de largo, cuya base fue formatizada terminando en punta para ser clavada y su extremo superior fue demarcado con la acanaladura vertical y las dos extremidades laterales. Algunas de las piezas similares (9 de las 35) han sido localizadas por comuneros de Anfama mientras labraban sus campos ${ }^{4}$.

En segundo lugar, se registraron cinco rocas intervenidas que se asocian a lugares de tránsito y espacios productivos (Tabla 1). Las mismas son de grandes dimensiones y pueden ser incluidas en el tipo 4 . Son grandes afloramientos rocosos que presentan conjuntos de cavidades circulares o hemiesféricas de distintas dimensiones formando diseños abstractos. Algunas de estas rocas, como la hallada en el sitio El Duraznillo (ED) presentan evidencias de haber sido usada recurrentemente a través de distintos momentos, ya que las cavidades se superponen entre sí borrando o alterando la demarcación de las anteriores (Figura 5, tipo 4).

En ambos casos, las rocas presentaron una buena visibilidad y al encontrarse fuera de estructuras pudieron ser divisadas desde cierta distancia. En algunos contextos además se asocian a recursos o lugares habitacionales lo que podría asociarse a la demarcación del territorio (Aschero 2007).

\section{Distribución en el paisaje}

De la misma forma en que el paisaje doméstico es continuo, las rocas intervenidas se distribuyen siendo partícipes de las configuraciones domésticas en cada sector habitado del valle. Las identificamos como un elemento recurrente en casi todas las ocupaciones investigadas y se identifican en cinco sectores principales: Residencial Intramuro: (a) los ingresos a las unidades residenciales, (b) en patios y (c) empotradas en las paredes de las viviendas. Extramuro: (d) campos de cultivo y (e) afloramientos rocosos. Fue posible identificar una distribución homogénea de las piezas sin concentrarse en un punto específico de la cuenca, como sí fue posible reconocer en el Valle de Tafí donde la mayoría se nucleaba en torno a un montículo de uso comunitario (García Azcárate 1996). Por otro lado, concibiendo al tiempo como dimensión fundamental del paisaje, los fechados radiocarbónicos realizados hasta la actualidad nos permiten proponer que las rocas de este tipo fueron manufacturadas y utilizadas especialmente en los primeros siglos de la Era cristiana. Las tipologías 1, 2 y 3 , representando a los tradicionalmente llamados menhires, se nuclean en los primeros siglos de la Era (siglos I DC al V DC). No tenemos evidencias de este tipo de rocas en momentos más tardíos, salvo aquellos casos reclamados y reutilizados con otro sentido, como observamos en El Sunchal (Figuras 3 y 7d). Esta particularidad -que es compatible con las interpretaciones cronológicas de los menhires asociados al montículo de El Mollar (Tartusi y Núñez Regueiro 1993)- remarca la importancia y los vínculos que las mismas podían tejer en los momentos de consolidación de los asentamientos aldeanos tempranos.

\section{Discusión}

En este trabajo se presentó una muestra de 35 rocas formatizadas -así como algunos artefactos implicados en su producción- que se manufacturaron, experimentaron y circularon en la cuenca de Anfama durante el primer milenio de la Era cristiana. Fueron caracterizados sus aspectos físicos, algo que ya se había logrado con numerosos objetos comparables en otras oportunidades (García Azcárate 1996), pero además se pudieron establecer algunas de sus relaciones con determinados escenarios de la práctica y en un proceso diacrónico.

Los fechados realizados en los contextos de hallazgo permiten proponer que la práctica de alterar bloques líticos en alguna de sus superficies, sus márgenes o su volumen se concentra en los primeros siglos de la Era cristiana. Esta asociación cronológica ya se había propuesto para los menhires hallados en el montículo de Casas Viejas, en el valle de Tafí (Tartusi y Núñez Regueiro 1993). Este momento se caracteriza por la emergencia y crecimiento de asentamientos aldeanos en numerosos sectores del NOA y la participación de estos marcadores materiales de lugares, recursos y paisajes es un fenómeno que puede aportar a la comprensión de las lógicas sociales que guiaron y se reprodujeron en este proceso. La intervención de las rocas y la elección de su posicionamiento y visibilidad se podría explicar como un búsqueda cotidiana de transmitir ciertos códigos 
coherentes a la representación ideal del mundo que tenían como grupo social (Troncoso et al. 2011).

La ubicación de estas rocas tiene relación con lugares de interacción y experiencia mutua y a su vez, en virtud de su durabilidad, están atravesadas por múltiples temporalidades (Lucas 2005). En ese sentido, por su carácter diacrónico tomamos ciertos recaudos a la hora de plantear interpretaciones fijas y generalizadas considerando que la asignación de significados esencializados, por ejemplo el de "huancas", no puede ser directa, puesto que presentar forma elongada, formatización y/o pulimentos superficiales no debería implicar inmutablemente esa interpretación (Dean 2010). Como sostiene Nielsen (2008), resulta dificultoso afirmar que todas estas rocas se concibieron como representaciones de los antepasados puesto que los muertos y sus descendientes se relacionaron en contextos cambiantes y, por consiguiente, "los ancestros" pudieron ser también otros seres (i.e. divinidades supernaturales) con numerosas significaciones en los diferentes escenarios políticos a lo largo de un milenio. Hageman y Hill (2016) plantean un punto central, a saber que la veneración de los ancestros no es una religión, sino un conjunto de creencias y prácticas dentro de un sistema cosmológico más amplio; y en contraparte, la intervención de rocas no es una referencia a los ancestros per se, sino una práctica integrada en numerosas negociaciones que exceden por mucho a las disputas de sus ejecutantes. Los objetos incluidos dentro de estas prácticas pueden haber variado, o muchos de los objetos que relacionamos a dichas veneraciones pueden haberse dado en el marco de otras.

En virtud de que resulta ambicioso dilucidar todas las relaciones en las que estuvieron implicados estos artefactos (Latour 2005), nos enfocamos en captar un fragmento de estos múltiples vínculos en el registro arqueológico reconociendo objetos, actividades y escenarios. Un elemento que destacamos se refiere a que las rocas intervenidas no se reducen a bloques elongados, tallados, pulidos y/o grabados -que se han reconocido como menhires o huancas-, sino que también existe una gran diversidad en sus características (i.e. pequeñas, grandes, elongadas, tabulares, rodadas, afloramientos, etc.), grados de intervención (i.e. tallados en bloque y pulidos, tallados marginalmente, grabados en toda su superficie, solo marcados, etc.), visibilidad (i.e. intramuros, extramuros, enfatizados o casi invisibles), o contextos de uso (i.e. cocinas, patios, lugares de paso, zonas exteriores de viviendas) en el marco de una misma modalidad de ejecución que incluye a casi todos los elementos analizados en una sola tradición ${ }^{5}$.

Esta variabilidad permite ampliar y diversificar los motivos que indujeron a la producción de bloques intervenidos y a las instancias y modos en las que los mismos mediaron efectivamente. Existen situaciones de experimentación de las rocas que son muy variadas.
Las marcas de cavidades hemiesféricas, en bloques de las caras internas de los muros, pueden haber sido visibles para los miembros de los grupos que ocupaban las viviendas. Como también se observa en la quebrada de Antofalla (Departamento Antofagasta de la Sierra, Catamarca) donde se emplearon bloques en el interior de los espacios residenciales con representaciones de animales (p.ej., camélidos) restringidos al grupo que habitaba ese espacio, esto es, en el centro de producción y reproducción de las relaciones domésticas (Haber 2006) ${ }^{6}$. La inclusión de bloques en muros puede haber tenido otros sentidos como objetos mnemotécnicos que podrían ser parte de celebraciones a la casa, como se registran etnográficamente en otros lugares de los Andes (Arnold 1992).

Los bloques mayores que formaban parte del escenario desplegado en los patios habrían tenido mayor visibilidad e incidencia en las relaciones entre los grupos sociales. Estos lugares constituían ámbitos nucleares para la reproducción de las familias, ya que articulaban todo el espacio de la casa, siendo los ordenadores de la circulación interna, presentando estructuras subsuperficiales destacadas, o rasgos destinados al almacenaje de alimentos. Finalmente, las piezas erigidas en lugares externos de las estructuras residenciales se constituían en partícipes directos de la legitimación del uso de ciertos sectores específicos del paisaje como viviendas.

De acuerdo a los análisis estratigráficos, estos objetos estuvieron circulando en distintos escenarios de la vida cotidiana y sobre todo en el marco de actividades domésticas sin diferenciarse, como en otros casos del Noroeste Argentino, en los espacios funerarios o en prácticas vinculadas a rituales específicos. En este sentido, no se observa en el contexto arqueológico la presencia de alguna delimitación particular para la interacción con estos objetos, ni su asociación a rasgos significativos como tumbas, montículos o materialidad muchas veces considerada de tipo ceremonial (Tartusi y Núñez Regueiro 1993). A su vez, tomando los planteos precedentes y basándonos en los registros etnohistóricos y etnográficos (Duviols 1973; Hageman y Hill 2016), si bien recalcamos que estos objetos tuvieron un rol fundamental como mediadores materiales en la interacción social y toma de decisiones cotidianas, se relacionaron en el marco de escenarios repetidos, de situaciones diarias (i.e. reuniones de numerosas personas, actos con parafernalia material, etc.) que reforzaron los vínculos domésticos, relaciones que parecen ser las preeminentes en las estructuras sociales y políticas articuladas en la época en la región bajo estudio.

En principio, muchas de las piezas fueron cambiando su escenario de mediación a lo largo de las ocupaciones. Por ejemplo, algunas rocas móviles de tamaño mediano pasaron a un proceso de reclamación dejando su lugar 
en los patios y recintos y se colocaron en las paredes de las viviendas construidas con posterioridad, tanto del primer milenio, como de momentos históricos, como fue registrado en ES (Figura 3).

En definitiva, las piedras intervenidas de las ocupaciones de los primeros siglos de la Era cristiana en este sector del NOA fueron objetos singulares en la construcción y reproducción de relaciones. Lo observado en el caso de Anfama es que su manufactura, distribución y uso estuvieron regulados por prácticas cotidianas de la vida doméstica. Su presencia habría sido central en el establecimiento de relaciones que se encontraban en constante tensión y negociación, propias del mundo aldeano temprano (Bandy 2010), para la reproducción social de las unidades domésticas, lo que habría permitido a su vez el acceso a determinados recursos tales como tierra, agua y otros derechos vinculados a la permanencia prolongada de un grupo en un mismo espacio. A lo largo de los primeros siglos del milenio estos objetos actuaron como guardianes de los intereses domésticos. No obstante, con el tiempo muchas de estas rocas fueron perdiendo cierta visibilidad y protagonismo y ya hacia principios del segundo milenio sólo se registran colocadas en los muros sin visibilidad, a modo de reclamación o desechadas fuera del contexto arqueológico.

Agradecimientos: Agradecemos a la Comunidad Indígena Diaguita de Anfama. A los miembros de EASCC, Dana Carrasco, Stefanía Chiavassa Arias, Ignacio Espeche, Francisco Franco, Lucía Justiniano, Rocío Molar, Juan Montegú, Gonzalo Moyano, y Agustina V. Fiorani por su colaboración en todos los trabajos de campo y numerosas tareas de gabinete. A los evaluadores anónimos, cuyas recomendaciones mejoraron sustancialmente la primera versión de este trabajo. El proyecto fue financiado por SECyT-UNC (Consolidar Res SECyT 411/18), SPU, CONICET (PIP_11220170100434CO), FONCyT (PICT-2016. 1738), Koeki Zaidan Hojin Toyota Zaidan (公益財団 法人トヨタ財団) The Toyota Foundation [TYTID: D16-R-0718], National Geographic Society (W46416).

\section{Referencias Citadas}

Adris, S. 2010. "El Buen Labrar": Ritual Productivo. Estudio de un caso de representaciones rupestres en espacios de producción agrícola. Actas del XVII Congreso Nacional de Arqueología Argentina, T. II, pp. 425-430. Universidad de Cuyo, Mendoza.

Albeck, M.E. 2001. La Puna Argentina en los Períodos Medio y Tardío. En Historia Argentina Prehispánica, editado por E. Berberián y A. Nielsen, pp. 347- 388. Editorial Brujas, Córdoba.

Albeck, M.E. 2010. Estudios de agricultura prehispánica: Casabindo (1980-1993). En Arqueología de la Agricultura. Casos de Estudio en la Región Andina Argentina, editado por M.A. Korstanje y M. Quesada, pp. 12-47. Magna, San Miguel de Tucumán.

Alfaro, L. 1988. Excavación de la Cuenca del Río Doncella. Reconstrucción de una Cultura Olvidada en la Puna Jujeña. Gobierno de la Provincia de Jujuy, San Salvador de Jujuy.

Alfaro, L. y J.M. Suetta 1970. Nuevos aportes para el estudio del asentamiento humano en la Puna de Jujuy. Revisión del Pucará de Rinconada. Antiquitas 10:1-10.

Ambrosetti, J.B. 1897. Los monumentos megalíticos del valle de Tafí (Tucumán). Boletín del Instituto Geográfico Argentino 18:105114.

Arnold, D. 1992. La casa de adobes y piedras del Inka. Género, memoria y cosmos en Qaqachaka. En Hacia un orden andino de las cosas, editado por D. Arnold, D. Jiménez A. y J. Yapita, pp. 31-109. Hisbol, La Paz.

Aschero, C. 1975. Ensayo para una Clasificación Morfológica de Artefactos Líticos Aplicada a Estudios Tipológicos Comparativos. Informe al CONICET, Buenos Aires.

Aschero, C. 1983. Ensayo para una Clasificación Morfológica de Artefactos Líticos. Apéndices A y B. Cátedra de Ergología y Tecnología, Buenos Aires.

Aschero, C. 2007. Iconos, huancas y complejidad en la Puna Sur Argentina. En Producción y Circulación Prehispánicas de Bienes en el Sur Andino, editado por A. Nielsen, M. C. Rivolta, V. Seldes, M. Vázquez y P. Mercolli, pp. 135-165. Editorial Brujas, Córdoba.

Astvaldsson, A. 1998. The Powers of hard rock: meaning, transformation and continuity in cultural symbols in the Andes. Journal of Latin American Cultural Studies 7 (2):203-223.

Babot, M.P. 2004. Tecnología y Utilización de Artefactos de Molienda en el Noroeste Prehispánico. Tesis de Doctorado en Arqueología, Facultad de Ciencias Naturales e Instituto Miguel Lillo, Universidad Nacional de Tucumán, San Miguel de Tucumán.

Bandy, M. 2010. Population Growth, Village fisioning and Alternative Early village trajectories. En Becoming Villagers: Comparing Early Village Societies, editado por M. Bandy y J.R. Fox, pp. 19-36. The University of Arizona Press, Tucson.

Berberián, E y A. Nielsen 1988. Sistemas de asentamiento prehispánico en la etapa formativa del valle de Tafí (Pcia. De Tucumán- Rep. Arg). En Sistemas de Asentamiento Prehispánicos en el Valle de Tafí, editado por E. Berberián, pp. 21-51. Editorial Comechingonia, Córdoba.

Bourdieu, P. 1977. Outline of a Theory of Practice. Traducido por R. Nice. Cambridge University Press, Cambridge.

Bourdieu, P. 2006. Campo del Poder y Reproducción Social. Elementos para un Análisis de la Dinámica de las Clases. Ferreyra Editor, Córdoba.

Callegari, A., M. Gonaldi, G. Spengler, M. Aciar, M. Rodriguez, R. Pappalardo y M. Wisnieski 2015. Tras las huellas del Formativo. Norte de la Provincia de La Rioja. En Crónicas Materiales Precolombinas. Arqueología de los Primeros Poblados del NOA, editado por M. Korstanje, M. Lazzari, M. Basile, F. Bugliani, V. Lema, L. Pereyra Domingorena y M. Quesada, pp. 247-275. Sociedad Argentina de Antropología, Buenos Aires.

Chambeaud, A. 2007. Políticas patrimoniales: los menhires de Tafí. Cuadernos de la Facultad de Humanidades y Ciencias Sociales 32: 73-89. 
Cobo, B. 1990 [1653]. Inca Religion and Customs. Ira edición. Traducido por R. Hamilton. University of Texas Press, Austin.

Dean, C. 2010. A Culture of Stone. Inka Perspectives on Rock. Duke University Press, Durham.

Duviols, P. 1973. Huari y llacuaz. Agricultores y pastores: un dualismo prehispánico de oposición y complementariedad Revista del Museo Nacional 39:153-187.

Duviols, P. 1979. Un simbolisme de l'ocupation, de l'amagement et de l'explotation de l'espace. Le Monolithe Huanca et sa fonction dans les andes Prehispaniques. L'Homme 19 (2):7-31.

Farfán Lobaton, C. 2012. El Huanca y su dimensión simbólica en la Arqueología de la Sierra Central. Arqueología y Sociedad 24:393-402.

Franco, F. 2019. La Práctica Alfarera durante el Primer Milenio de la Era en el Sunchal, Anfama (Dto. Tafi Viejo, Tucumán, Rep. Argentina). Trayectorias de Vida, Cadenas Operativas y ¿Tradición? Tesis de Licenciatura, Facultad de Filosofía y Humanidades, Universidad Nacional de Córdoba, Córdoba.

García Azcárate, J. 1996. Monolitos-huancas: un intento de explicación de las piedras de Tafí (Rep. Argentina). Chungara Revista de Antropología Chilena 28 (1-2):159-174.

García Azcárate, J. 2000. Símbolos, piedras y espacios: una experiencia semiológica. En Arte en las Rocas. Arte Rupestre, Menhires y Piedras de Colores en Argentina, editado por M. Podestá y M. De Hoyos, pp. 73-83. Sociedad Argentina de Antropología, Buenos Aires.

González, A.R. 2004. La arqueología del Noroeste argentino y las culturas formativas de la cuenca del Titicaca. Relaciones de la SAA 29:7-38.

González, A.R. y V. Núñez Regueiro 1960. Preliminary Report on Archaeological Research in tafí del Valle, NW Argentina. En Akten del 34 amerikanisten Kongress, pp. 18-25. Viena.

Guffroy, J. 1999. El Arte Rupestre del Antiguo Perú. Institut Français d'Études Andines, Institut de Recherche pour le Développement, Lima

Haber, A. 2006. Una Arqueología de los Oasis Puneños. Jorge Sarmiento Editor, Córdoba.

Hageman, J. y E. Hill 2016. Leveraging the Dead: The Ethnography of Ancestors. En The Archaeology of Ancestors: Death, Memory, and Veneration, editado por E. Hill y J. Hageman, pp. 4-41. University Press of Florida, Gainesville.

Harris, E. 1991. Principios de Estratigrafía Arqueológica. Editorial Crítica, Barcelona.

Janusek, J.W. 2015. Of monoliths and men: Human-lithic encounters and the production of an animistic ecology at Khonkho Wankane. En The Archaeology of Wak'as. Explorations of the Sacred in the Pre-Columbian Andes, editado por T. Bray, pp. 335366. University Press of Colorado, Boulder.

Lazzari, M., J. García Azcárate y C. Scattolin 2015. Imágenes y memoria: las presencias ancestrales en el Formativo. En Crónicas Materiales Precolombinas. Arqueología de los Primeros Poblados del Noroeste Argentino, editado por M. Korstanje, M. Lazzari, M. Basile, M. Bugliani, V. Lema, L. Pereyra Domingorena y M. Quesada, pp. 603-633. Sociedad de Antropología Argentina, Buenos Aires.

Latour, B. 2005. Reassembling the Social: An Introduction to Actor Network-Theory. Oxford University Press, Oxford.

Lucas, G. 2005. Archaeology of Time. Routledge, London.

Martiarena, L.M. 2014. The Social Life of Death: Mortuary Practices in the North-Central Andes, 11th-18th Centuries. PhD Dissertation, Sainsbury Research Unit for the Arts of Africa, Oceania \& The Americas School of Art History and World Art Studies, University of East Anglia, Norwich.

Meskell, L. 2005. Archaeologies of Materiality. Blackwell, Oxford.
Mills, B.J. 2008. Remembering while forgetting: depositional practices and social memory at Chaco. En Memory Work: Archaeologies of Material Practices, editado por B.J. Mills y W.H. Walker, pp. 81-108. School for Advanced Research Press, Santa Fe.

Nielsen, A.E. 2006. Plazas para los Antepasados: Descentralización y Poder Corporativo en las Formaciones Políticas Preincaicas de los Andes Circumpuneños. Estudios Atacameños 31:63-89.

Nielsen, A.E. 2007. Armas significantes: tramas culturales, guerra y cambio social en el sur andino prehispánico. Boletín del Museo Chileno de Arte Precolombino 12:9-41.

Nielsen, A.E. 2008. The materiality of ancestors. Chullpas and social memory in the Late Prehispanic history of South Andes. En Memory Work: Archaeologies of Material Practices, editado por B. Mills y W. Walker, pp. 207-231. School for Advanced Research Press, Santa Fe.

Núñez Regueiro, V. y M. Tartusi 2002. Aguada y el proceso de integración regional. Estudios Atacameños 24:9-19.

Oliszewski, N. 2018. Las aldeas "Patrón Tafi" del sur de Cumbres Calchaquíes y norte del sistema del Aconquija. Comechingonia 21 (1):205-232

Pérez Gollán, J.A. 1992. La Cultura de La Aguada vista desde el valle de Ambato. Publicaciones del CIFFyH 46: 157-173.

Pérez Gollán, J.A. 2000. El jaguar en llamas. La religión en el antiguo Noroeste argentino. En Nueva Historia Argentina los Pueblos Originarios y la Conquista, editado por M. Tarragó, T. I, pp. 229-256. Editorial Sudamericana, Buenos Aires.

Quiroga, A. 1899. Ruinas de Anfama. El pueblo Prehistórico de la Ciénega. Boletín del Instituto Geográfico Argentino 95-123.

Rapoport, A. 1990. System of activities and systems of settings. En Domestic Architecture and the Use of Space. An Interdisciplinary Cross-Cultural Study, editado por S. Kent, pp. 9-20 Cambridge University Press, Cambridge.

Robin, S. 2010. An Archaeology of the Senses: Prehistoric Malta. Oxford University Press, Oxford.

Salazar, J. 2011. Reproducción Social Doméstica y Asentamientos Residenciales entre el 200 y el 800 d.C. en el Valle de Tafi, Provincia de Tucumán. Tesis Doctoral, Facultad de Filosofía y Humanidades, Universidad Nacional de Córdoba, Córdoba.

Salazar, J. y R. Molar 2017. Estudio comparativo de dos sitios aldeanos del primer milenio d.C. en Tucumán, Argentina. Comechingonia. Revista de Arqueología 21:123-148.

Salazar, J., V. Franco Salvi y E. Berberián 2011. Una aproximación a la sacralidad de los espacios domésticos del primer milenio en Valle de Tafí (Noroeste Argentino). Revista Española de Antropología Americana 41:9-26.

Salazar, J., R. Molar, J. Montegú, F. Franco, A. Vázquez Fiorani, G. Moyano, S. Chiavassa-Arias, D. Carrasco y V. Franco Salvi 2019. Investigaciones arqueológicas en la cuenca de Anfama, Provincia de Tucumán. Librode Resúmenes del XX Congreso Nacional de Arqueología Argentina, pp. 195-199. Universidad Nacional de Córdoba, Córdoba.

Schreiter, R. 1928. Monumentos megalíticos y pictográficos en los Altivalles de la provincia de Tucumán. Boletín del Museo de Historia Natural Tomo II (1):1-9.

Sillar, B. 2009. The social agency of things? Animism and materiality in the Andes. Cambridge Archaeological Journal 19:367-377.

Tarragó, M. 1974. Aspectos ecológicos y poblamiento prehispánico en el Valle Calchaquí, provincia de Salta, Argentina. Revista del Instituto de Antropología 5:195-216.

Tartusi, M. y V. Núñez Regueiro 1993. Los Centros Ceremoniales del NOA. En Publicaciones del Instituto de Arqueología 5:1-93.

Tilley, C. 2007. Materiality in Materials. Archaeological Dialogues 14 (1):16-20 
Troncoso, A, F. Criado-Boado y M. Santos-Estévez 2011. Arte rupestre y códigos espaciales: Un caso de estudio en Chile Central. Chungara Revista de Antropología Chilena 43 (2):161-176
Toselli, A., J. Basei y M. Rossi 2003. Análisis geoquímicogeocronológico de rocas granulíticas y calcosilicáticas de las Sierras Pampeanas Noroccidentales. Revista de la Asociación Geológica Argentina 58 (4):629-642.

\section{Notas}

${ }^{1}$ En base a registros etnográficos se define al término huanca como una piedra oblonga y empinada con forma y tamaño variable. Puede ser lisa o labrada. En general se ubican en los lugares ilustrados por los hechos de los antepasados que están ligados con la fecundidad, esto es, en las chacras, próximo a un puquio creado por un antepasado, cerca de una acequia, a la entrada del pueblo (Duviols 1973:163).

2 Toselli et al. 2013 detectaron en el área esquistos bandeados que se presentan en forma de lentes y bancos de pocos centímetros a decímetros de espesor. Se caracterizan por su grano fino y aspecto hornfelsoide y, por sus condiciones físicas de metamorfismo, se corresponden a la serie cianita-sillimanita (Toselli et al. 2003:631). En la zona abundan las rocas metamórficas, tanto calcosilicatosfacies-esquistos verdes-anfibolitas como las calcosilicatos facies granulitas (Toselli et al. 2003).

${ }^{3}$ Esta misma asociación se observa también en otros sitios del área como El Zapallito y Aliso Redondo.

${ }^{4} \mathrm{Si}$ bien es difícil arriesgar algún tipo de asociación de las mismas, ya que son objetos recuperados por comuneros/as sin ningún tipo de registro, según sus dichos todos los hallazgos se produjeron en espacios abiertos que ellos usan para sembrar maíz, y no estaban asociados a muros u otros rasgos.

${ }^{5}$ La única excepción es la intervención de dos motivos ornitomorfos superpuestos a un mascariforme doble ejecutado en un bloque hallado en el piso ocupacional de la U4 de MQ (Figura 7a). En este caso los grabados superficiales son completamente distintos a todos los diseños registrados y quizás sean asimilables a los ejecutados en zonas altas de las Cumbres Calchaquíes (Adris 2010).

${ }^{6}$ En otros sectores de las cumbres calchaquíes se registran ejemplos de rocas talladas con formas oblongas. Vale destacar un sitio denominado Campo Colorado (Tarragó 1974) correspondiente al primer milenio de la Era. Las habitaciones se asocian a campos de cultivo y se destacan entre la materialidad del sitio, además de pipas angulares de cerámica y uso de metales, la presencia de esculturas de piedra con representaciones fálicas o siluetas zoomorfas apenas insinuadas tanto en los muros de las viviendas como en basureros (Tarragó 1974). Más al sur, al pie de la Sierra de Santa Ana, en el sector NE de Campo de Pucará también se registraron rocas esculpidas (sitio El Alamito) (Tartusi y Nuñez Regueiro 1993). González (2004) menciona el hallazgo de una figura de piedra, femenina, de casi un $m$ de alto, la cual representaba una imagen de alter ego, con una mutilación en la cabeza y que a sus pies estaba acompañada por un plato de piedra de forma circular. Finalmente, es importante resaltar la presencia de "menhires" en el valle de Antinaco (departamento Famatina, norte de La Rioja), en el sitio denominados Cerro La Cruz 1 se identificaron dos menhires con motivos abstractos que aún permanecen en pie, en un área abierta y adyacente a unidades residenciales (Callegari et al. 2015). En diversos sitios de la Puna de Jujuy se han registrado piedras similares a las que nos referimos en este trabajo, por ejemplo, en Pueblo Viejo de Tucute (Albeck 2001) -sector Loma Alta- fueron identificados recintos de planta rectangular con menhires en su interior, en un caso, cilíndricos, en el otro, prismáticos (Albeck 2010). En Doncellas, los complejos residenciales también presentan en algunos casos menhires cilíndricos de piedra en sus muros (Alfaro y Suetta 1970; Alfaro 1988). A su vez, en el Pucará de Rinconada (Albeck 2001; Alfaro y Suetta 1970) se hallaron rocas cilíndricas talladas en recintos residenciales de planta rectangular. 